\title{
LA MENTE CRIMINAL Y LA VIOLACIÓN DE DERECHOS HUMANOS
}

\author{
Lic. Juan Carlos Martínez Colmenares ${ }^{1}$ \\ Dr. José Antonio Morales Notario ${ }^{2}$
}

\begin{abstract}
: criminal behaviors have always been present in the lives of human being. People learn to live in an increasingly complicated world, in which complications are not proportional to the damage caused by the offender. Since the genesis of humanity, the human being has pretended to find an explanation to criminal acts; however, the play and role that the victim plays has been neglected. In the case of crimes that involve women as a passive subjects of a crime, such as gender crimes, the criminal law has tried to explain the criminal thinking, but without analyzing the role of the victim or the damage caused. The offence causes harm not only to the person who suffers but the surrounding environment such as parents, children, family, friends and the community itself
\end{abstract}

Keywords: victim, damages, crime,

criminal behavior

\section{Genesis de las conductas sancionadas por las leyes \\ En un principio se tuvo la} necesidad de sancionar todas aquellas acciones que vulneraban al grupo social. El ser humano aún no articulaba palabra alguna, pero ya desarrollaba conductas que afectaban a los demás integrantes del grupo, tales como el apoderamiento ilegítimo del animal cazado por otro, o la violencia física que se ejercía contra la mujer (Amuchategui, 2005).

Por esa razón, al existir la necesidad de crear leyes que mantuvieran el orden jurídico establecido, se creó el castigo para todo aquel que violara la norma; pues se considera que la vulneración de ésta, da como resultado una acción antisocial y dañosa que perjudica a la sociedad y al

\footnotetext{
${ }^{1}$ Licenciado en Derecho y Egresado de la Maestría en Administración de Justicia de la División Académica de Ciencias Sociales y Humanidades de la Universidad Juárez Autónoma de Tabasco.

2 Doctor en Derecho y Profesor Investigador adscrito a la División Académica de Ciencias Sociales y Humanidades de la Universidad Juárez Autónoma de Tabasco.
} 
orden social (Pavón, 1991); surgiendo de esta manera la idea de sanción.

Las primeras etapas de la humanidad estuvieron determinadas por la proporción que se intentó fijar al daño que se causaba por la conducta que las leyes sancionaban y el castigo que debía recibir el delincuente. La Ley del Talión fijó el principio de proporcionalidad al establecer el "ojo por ojo, diente por diente". Platón, en su obra "Las Leyes" señaló que era necesario encontrar la proporcionalidad de la pena con la gravedad del delito (Yenissey, 2009) y no fue son hasta el momento en que el Estado establece como mandato constitucional, que éste cuenta con la facultad para imponer una pena o una medida constitucional y adecuada, como consecuencia jurídica de la posible aplicación para aquel que ha infringido la norma.

La conducta considerada lesiva para la comunidad tenía un castigo, el cual nace precisamente con la idea de Estado. No se puede concebir la existencia de una sociedad sin la presencia de un orden coactivo. El castigo que se imponía a quien violentaba el orden jurídico establecido debía ser castigado; sin embargo, éste variaba de acuerdo con el modo producción y la época.

Antes de la edad media, el castigo no era solamente una sanción para quien hubiera cometido un crimen, sino que era una afrenta para el poder del gobernante, el cual estaba obligado a imponer una pena que fuera eficaz. Mientras más público fuera el escarnio y el sufrimiento del condenado, más grande sería el respeto que el pueblo le rendiría al soberano, quien era considerado como el representante de la ley, del Estado y de Dios (Sammara de Araújo, 2017).

Durante mucho tiempo, la iglesia fue la institución encargada de fijar las sanciones; sin embargo, comenzó a existir un desequilibrio entre el daño y la sanción, puesto que esta última consistía en castigos que trascendían al delito y al delincuente. La pena era considerada como una manifestación de enemistad contra el soberano. Por ello, la primera institución punitiva es la inquisición administrada por la iglesia, la cual indagaba hasta provocar la confesión, que era el modo de revertir el estado de pecado, entendido como característica personal que el delito sólo ponía de manifiesto. 
Originalmente se buscaba sancionar la herejía a través de un proceso inquisitorial; sin embargo, el castigo buscaba neutralizar la enemistad con el soberano (Gamboa, s.f.).

En el "Tratado de los delitos y de las penas", su autor realiza una crítica al sistema existente y duda de las creencias relacionadas con la eficacia de la pena (González-Salas, 2001). César Beccaria (2015) señaló que las leyes son las condiciones por las cuales los hombres independientes y aislados se unieron en sociedad, al estar cansados de vivir en continua guerra y ante la incertidumbre de una libertad que no disfrutaban por el temor de no poder conservarla. El soberano era el administrador y legítimo depositario de la soberanía de una nación y por ello, era necesario defenderla. Cuando el hombre quiere sumergir las leyes de la sociedad en un caos, se establecen las penas contra los infractores. Toda pena, de acuerdo a Montesquieu, que no deriva de la absoluta necesidad, es tiránica. De ahí surge la necesidad de defender la seguridad de todo individuo.

Ninguna persona ha cedido su libertad de manera gratuita; a través de este acto, se busca el bien público y así ha sido desde los primeros salvajes. Es la necesidad quien obligó a los seres humanos a ceder lo más valioso para ellos; sin embargo, a través de la porción más pequeña de esta, se busca que se defienda y de ahí nacen el derecho a la justicia por medio del castigo; que precisamente, no dimana de Dios, sino de la misma necesidad de protección (Beccaria, 2015).

Si bien es cierto el ser humano se ha visto en la necesidad de crear leyes para poder mantener el control social entre todos los habitantes; el castigo entonces, debía ser proporcional al daño que se causa. Esto, obviamente fue atacado por quienes defendían la fe católica y, en consecuencia, el libro de Beccaria fue prohibido, sin tomarse en consideración que lo que proponía era la prevención y la readaptación como medio para evitar que el sujeto reincida; en otras palabras, contraponía los intereses del antiguo régimen y proponía un derecho penal más humano, más benigno, más proporcional y más cierto (Rodríguez, 2011).

Beccaria llama a la reflexión sobre el concepto de daño social y la defensa de lo social como elemento indispensable para el Estado de Derecho. 
Por ello, establece un nuevo paradigma en la formulación de una nueva teoría jurídica del delito y de la pena, así como del proceso. El delincuente es un sujeto humano, racional, aunque es anormal, moldeado por factores genéticos, psicológicos o sociales, $\mathrm{y}$ hasta cierto punto, incapaz de resistir la tendencia inherente hacia una conducta criminal (Rodríguez, 2011).

Michel Foucault (2003) difiere de Beccaria y señala que hay que castigar de otra manera, deshacer el enfrentamiento físico del soberano con el condenado principalmente cuando se desarrolla entre la venganza del monarca y la cólera contenida del pueblo, por intermedio del ajusticiado y del verdugo. El suplicio es intolerante, irritante por el lado del poder, que utiliza la tiranía, el exceso de sed de venganza y placer en el castigar. La humanización de las penas se debe más a razones estructurales, particularmente económicas pues es mejor y se obtienen mejores beneficios si se disciplina al sujeto y se obtiene alguna utilidad de él. Ahora bien, no hay que olvidar a la víctima, a la cual se reduce a la desesperación y al sentimiento de abandono por parte de las autoridades; por ello es preciso que la justicia castigue al fin $y$ no busque venganza. Es necesario un castigo sin suplicio ya que aún al peor de los asesinos se le debe de respetar su humanidad.

Foucault indica que la verdadera aspiración de la proporcionalidad de los castigos de los reformadores, no está en la reducción del dolor del castigo en relación al delito, sino que está en relación con la utilidad conseguida con la pena: a mayor efecto disuasivo, mayor utilidad del castigo y su intensidad. Lo que se busca es corregir la delincuente y disciplinarlo. Con esto se consiguen diversas ventajas: a) el castigo deriva de la naturaleza del delito y no del poder entre el soberano y el delincuente; b) la sanción es evidenciada al ser un órgano competente el que la emite, pero el castigo es oculto a los ojos de los hombres ya que las penas se cumplen en lugares como prisiones o cárceles; y, c) los castigos ya no son considerados una vergüenza por quienes administran la justicia (Carrasco, 2007).

El hombre al delinquir no se encuentra fuera de la ley, sino fuera de la naturaleza, violentando con esto el pacto social, regresando a un estado de barbarie $\mathrm{y}$, en consecuencia, debe ser visto como un enemigo común dentro de 
la sociedad. Rousseau afirmaba que cualquier malhechor, cuando atacaba al derecho social, era considerado un rebelde y traidor a la patria. Cuando se vulneran las reglas que la sociedad ha impuesto entonces se deja de ser uno de sus miembros y se hace la guerra posición extremista- por ello, es necesario que perezca. El proceso y la sentencia son las evidencias de que el pacto social se ha roto y en consecuencia no es considerado ya un integrante más del Estado y se justifica el derecho de la guerra de matar al vencido pues se considera incompatible la conservación del Estado con el sujeto que violenta la norma (Carrasco, 2007).

La prisión actualmente es vista como una medida de control social pues se sigue prefiriendo a la pena y no al delincuente. El tiempo en prisión, es considerado parte del tiempo inquisitorial; pues muchas personas perecen en su cautiverio, derivado de las propias riñas internas, derivadas de discusiones por espacios o por un simple vaso con agua. La prisión no representa la rehabilitación del delincuente ni mucho menos los presupuestos jurídicos de la Ley de Normas Mínimas Mexicana. Lo cierto es que ningún reo se readapta o se rehabilita, sólo se acostumbra a vivir en la prisión si sobrevive en ella (Gamboa, s.f.).

\section{¿Por qué la persona delinque?}

La maldad, desde un punto de vista psicoanalítica, puede ser definida como la capacidad de un sujeto para ejecutar la destrucción de otro. Esa capacidad destructiva puede estar dirigida hacia la destrucción de una persona, la sociedad en general; un grupo específico de personas, animales o bienes materiales específicos. Por esa razón, la humanidad ha tenido que crear códigos que definan la conducta aceptable para vivir en sociedad. Ejemplos de esto es el código de Hammurabi en Mesopotamia o el Código de Moisés. A través de la codificación se pretendía imponer un límite y un orden a la acción destructiva del ser humano (Lander, 2017).

En ocasiones, esa maldad es el resultado del ambiente en que una persona se desenvuelve o bien parte de padecimientos físicos o mentales. A veces, el sujeto ve un medio para obtener situaciones ventajosas, como el caso de aquella persona que después de quedarse viudo, comenzó a interrelacionarse con 
diversos tipos de mujeres y al abusar de la famosa píldora azul, padeció una enfermedad que lo dejó convaleciente, sin movimiento. En ese caso, sus hijos se hicieron cargo de él al no poder depender por sí mismo, pero durante más de 10 años, al ser considerado, además, adulto mayor, la ley obligaba a sus familiares a prestarles auxilio, siendo que esta persona abusaba de su condición y lo utilizaba como un medio de manipulación hacia su familia.

La explicación pudiera ser sencilla: por un lado, el ser humano es inherentemente malo, visto desde una posición teológica, es decir, de causa y finalidad. Como la maldad es propia y personal, el control social que se ejerce contra él, sirve como medio para reprimir sus impulsos y actuar en beneficio de la sociedad en búsqueda del bien común. La comunidad humaniza al hombre $y$ sus sistemas políticos mantienen a raya cualquier atisbo de maldad. La creación de leyes constituye un medio para frenar el daño que podría causarse si las conductas lesivas no estuvieran prohibidas. Ahora bien, todo dependerá del tiempo y modo en cómo se realice esta actividad, porque en ocasiones, en cumplimiento de las leyes, se actúa de tal forma que se vulneran derechos de terceros, como es el caso en los que, bajo el argumento de la civilización y de la inculcación de la religión, se recurre al asesinato para el bien de la humanidad, ejemplo de ello, la conquista de América; o bien, el movimiento nazi que dio origen a la segunda guerra mundial. Existe otra postura que considera al individuo como puro y sin malicia y precisamente cuando se relaciona con otros seres de su especie que surge la maldad; ante ello, en contrato social y la sociedad en sí, forman una fuerza degeneradora $\mathrm{y}$ desmoralizadora del hombre que tiene como objetivo disuadir a los individuos (Hermitaño, 2007).

Lo cierto es que el ser humano siempre ha tratado de explicarse las razones por las cuales una persona actúa de cierta manera, enfocándose principalmente en quien delinque. Para ello ha creado una ciencia a la que ha denominado criminología, que tiene como objeto el estudio de la criminalidad, de las personas a ellas vinculadas y de la reacción social que pueda suscitar; abarca a la delincuencia, la delincuencia tipificada en los diferentes códigos y leyes y también a 
aquella que, sin estarlo, se aparta de las normas sociales establecidas y que, por lo tanto, genera rechazo tanto de la sociedad como de las instituciones. La respuesta que la sociedad y los órganos del Estado dan al fenómeno del delito se representa mediante mecanismos de represión, prevención, despenalización, judicialización y descriminalización (Yurgaqui, 2017).

César Lombroso (Montenegro, 2015), connotado estudioso de la conducta del delincuente determinó que el delito era el resultado de tendencias innatas, de orden genético, derivado de ciertos rasgos físicos o faciales de los delincuentes habituales, destacando la asimetrías craneales, determinada forma de las mandíbulas, las orejas, los arcos superciliares, etc.; sin embargo, hay otros factores a considerar como lo son el clima, el lugar, el grado de civilización, la densidad de la población, la alimentación, la drogadicción, la instrucción, la situación económica e incluso las creencias religiosas.

Es importante indicar que esta tendencia ha quedado sobrepasada cuando en la actualidad se hablan de otros factores que requieren de un análisis más a profundidad, desde un enfoque multidisciplinario que permitan determinar el nivel psicológico del individuo. La delincuencia se deriva de la desadaptación del individuo a) para adaptar su conducta al medio en que se encuentra; b) por su frustración a lograr el éxito debido a las exigencias que el propio medio le impone, derivada de una incapacidad física o mental; c) como una forma adoptada de forma de conducta que lo aleja de la convivencia armónica y constructiva. Esta inadaptación se manifiesta a través de: a) la evasión del hogar, de la escuela o de la sociedad; b) la inadaptación social; c) el suicidio; d) la mentira; e) el robo y f) la perversión sexual en todas sus formas (homosexualidad, prostitución o libertinaje) (Montenegro, 2015).

El problema radica en que en la actualidad encontramos que las conductas delictivas se cometen a una edad más temprana $\mathrm{y}$ en muchas ocasiones no importa el factor social ni el económico, pues el delito no se circunscribe a una clase social determinada. Los adolescentes, por citar un ejemplo, muestran que las relaciones paterno-filiales no son motivo de discrepancia o cambio en cuanto a su conducta, puesto que en un estudio 
realizado en Santo Domingo por Aida Mencia-Ripley (2016), los resultados mostraron una mayor vinculación $\mathrm{y}$ calidad en la relación con sus padres; sin embargo, los factores de riesgo lo constituyen la impulsividad, las emociones y contingencias de reforzamiento conductual, la disregulación afectiva así como la presentación de oportunidades para delinquir acompañada de la falta de consecuencias pues al ser menores de edad, sus acciones u omisiones no son consideradas conductas delictivas sino infracciones a las normas.

Existen factores endógenos como son la herencia; endocrinológicos como la edad, o una enfermedad toxicoinfecciosa; y también exógenos dentro de los que se ubican los tipos y circunstancias en las que se desarrolla el individuo dentro de la familia; incluyendo los valores que se le inculcan, la comunicación que tiene con sus padres y familiares y el papel que asumen estos últimos en cuanto a la educación de las niñas, niños, adolescentes y jóvenes; aunque en las últimas décadas ha tenido un mayor impacto la desorganización familiar (Mata, 2003).
Los factores criminógenos se pueden clasificar en tres grupos: los sociales, los psicológicos y los biológicos. El factor médico-psicológico intenta explicar la conducta infractora, pero descarta lo sociológico o económico, focalizándose principalmente en el autor del hecho y su carácter en general. Esto es derivado en la división que se hace del elemento psicosomático y los factores biológicos y lo psicológico (Mata, 2003). La modernidad y el libertinaje ha traído como consecuencia un aumento considerable en el porcentaje de menores infractores; a esto se agrega la alimentación y las continuas zozobras y angustias por la pérdida de sus seres queridos, los temores de perder la vida o la salud y el radical cambio del mundo circundante, que produce una generación especializada en actos antisociales.

Otro elemento a destacarse es la falta de atención de los padres en la formación de sus hijos a quienes abandonan y dejan en manos, en ocasiones de las personas de servicio, o de las malas compañías. La vagancia, el ocio y la mendicidad producen, entre otras conductas, los vicios y el robo. El núcleo central de la sociedad es la 
familia y al estar desorganizada no es capaz de educar y cuidar a los menores. Los padres prefieren darle libertad a sus hijos en vez de brindarles ejemplos positivos que redunden en su propio beneficio; proporcionando el espacio ideal al ocio, a la falta oportuna y adecuada de educación, las malas compañías, las visitas a los antros de vicio e incluso, la iniciación en costumbres consideradas depravadas (Mata, 2003).

Si a esto se agrega la falta de atención por parte de las autoridades, las cuales prefieren suponer en vez de averiguar, aunado a la falta de castigo o consecuencia para los funcionarios que realizan mal su trabajo o para los que delinquen, ya que el juez es capaz de negar la existencia de un crimen a pesar de que exista toda la evidencia para probarlo, o bien, puede condenar a un inocente. Entonces, tenemos cárceles repletas de individuos que deben cumplir una condena por la comisión de algún delito y al egresar, serán conocedores de otros, ya que mientras estén privados de su libertad, tendrán la oportunidad de compartir sus experiencias con otras personas, las cuales harán lo propio, creándose una escuela del crimen.
Desafortunadamente los centros carcelarios no están cumpliendo con su obligación de reinsertar al delincuente a la sociedad. En un principio se buscaba la readaptación, pero el ser humano no necesita ser readaptado ya que significaba que el pensamiento que dictaba su actuar era inadaptado. El delito no es desadaptación, sino que puede derivar, como se ha señalado de factores ajenos a la voluntad del sujeto. Existen dos tipos de delitos: los intencionales o doloso y los cometidos sin esa voluntad de causar un daño o dolosos. En ambos casos, el aparato gubernamental actúa contra el sujeto, con la finalidad de que sirva de ejemplo para los demás, pero también para desalentarlo con el objetivo de que no vuelva a delinquir. Sin embargo, cada ser humano es diferente y el error más común es considerar que son las instituciones y tradiciones las que determinan la naturaleza del criminal, siendo todo lo contrario (Huertas-Díaz, 2011).

\section{4.- La neurociencia}

Desde el punto de vista sociológico, se ha determinado que el comportamiento del ser humano a lo 
largo de la historia tiende a manifestarse de diversas maneras, siendo la violencia una forma de conducta que, para satisfacer los instintos criminales formados a través del tiempo, da como resultado la subsistencia del crimen y el delito. Si bien es cierto, el entorno y el espacio donde se desenvuelve una persona determinan ciertas características que se manifiestan en su vida, éstos elementos no son concluyentes. También se ha señalado que las características geográficas inciden en la conducta de los individuos pues donde existen menos posibilidades de trabajo y de progreso, surgen actividades ilícitas como medio para generar los recursos necesarios para subsistir en ese ambiente y bajo esas condiciones (Sandoval \& Martínez, 2008).

Como parte de una revolución científica que está aportando explicaciones a la forma de actuar del ser humano, surge la neurociencia. La mayoría de las ocasiones, los individuos realizan conductas que, aunque están prohibidas por las leyes por el daño que causan, son cometidas a pesar de la amenaza de un castigo. Esto obliga a tratar de entender el fenómeno a nivel cerebral tomando en consideración que el funcionamiento de este favorece el conocimiento y la comprensión de anormalidades neurobiológicas que causan desórdenes mentales y neurológicos. El objetivo principal de esta nueva ciencia es entender como el encéfalo produce la marcada individualidad de la acción humana y explicar cómo actúan los millones de células nerviosas individuales para producir la conducta, influenciadas por el medio ambiente y la conducta de otros individuos (Ichard, S.f.).

¿Qué es lo que pasa por la mente de las personas? Todos los individuos tienen tendencia hacia el bien y el mal, pero unos desarrollan una conducta más que otra. La neurociencia, estudio interdisciplinar de la mente que surge en los años 60, intenta explicar la naturaleza de los estados mentales, ayudada por la neuroanatomía, electrofisiología, mecanismos celulares y moleculares subyacentes a los procesos psicológicos de mayor complejidad. Existe una vinculación entre la mente y el cerebro y ello obliga a conocer la estructura y funcionamiento del sistema nervioso; principalmente por los nuevos 
hallazgos sobre el cerebro (Blanco, 2014).

La tarea central de la neurociencia es la de intentar explicar cómo actúan millones de células nerviosas individuales en el encéfalo para producir una conducta y cómo, a su vez, estas células son influenciadas por el medio ambiente y la forma de conducirse de otros individuos. Lo que se busca es una mejor comprensión y respuestas a cuestiones que interesan no sólo a los educadores, sino a todos aquellos interesados en saber cómo funciona el cerebro; claro, desde una perspectiva multidisciplinar. Por ejemplo, la neuropsicología está interesada en estudiar las relaciones entre el cerebro y la conducta, por las bases neuroatómicas de los comportamientos superiores y las patologías que tienen un mayor desarrollo en el ser humano como lo son: el lenguaje, la memoria, la orientación espaciotemporal, el esquema corporal, la psicomotricidad, las gnocias, las praxis y las asimetrías cerebrales, en virtud del funcionamiento global del cerebro (De la Barrera, 2009).

El reto de la neurociencia es comprender como funciona el cerebro
158 para producir mente y conducta; en otras palabras, se encarga de los mecanismos fisiológicos, evolutivos y de desarrollo de la conducta y la experiencia. Luigi Galván descubrió la actividad eléctrica del sistema nervioso y aseguró que existe un desequilibrio entre el interior $\mathrm{y}$ el exterior de las fibras musculares, siendo una fibra nerviosa la que penetra en éstas a través del flujo eléctrico. Julien Offray de la Mettrie indicó que el pensamiento es producto del cuerpo y en particular del cerebro. Santiago Ramón y Cajal, propuso que las neuronas son células separadas entre ellas, independientes y unidades funcionales del sistema nervioso (Annicchiarico, Gutiérrez, \& Pérez-Acosta, 2013). No es sino a finales de los 90 que se evalúa las posibilidades de las neurociencias para la comprensión y la resolución delas enfermedades mentales, teniendo como base el desarrollo de la genética molecular, la bioquímica en general y los estudios comparados del comportamiento; todo basado en tres premisas: 1) el cerebro se comunica con el cuerpo a través de los nervios y mediante la electricidad; 2) las lesiones que sufre el sistema nervioso afectan a las sensaciones (emociones) el movimiento y al propio pensamiento; y, 
3) el cerebro tiene distintas parte identificables como la percepción, la emoción y el lenguaje (Redolar, 2002).

Al dedicarse el estudio de la neurociencia a verificar todo tipo de vinculación entre el funcionamiento del cerebro y la conducta, abarca las disfunciones en los circuitos neuronales que afectan al control emocional que generan conductas violentas o como incide a reducción de la masa cerebral prefrontal en el desorden de la personalidad antisocial. Pero para llegar a este punto, se toman en consideración todo tipo de consideraciones pues lo que se busca es comprender y explicar las razones de la conducta propia y ajena, siempre bajo las circunstancias que pueden influir en esto como son las materiales (sociales y externas), los factores biológicos, los rasgos del carácter, las condiciones ambientales o medio cultural, entre otras; principalmente porque todos estos elementos forman parte de un conjunto complejo y heterogéneo que condiciona, influye y causa el comportamiento de los individuos (Narvaez, 2014).

Entonces, ¿existe la libre determinación de la voluntad para tomar decisiones, principalmente en el campo del desarrollo de la conducta, si el comportamiento del ser humano está condicionado por factores externos $\mathrm{y}$ sociales?

Gerard Roth (Crespo, 2014) asegura que la voluntad del ser humano se transforma en hechos concretos cuando su yo consciente realiza alguna acción voluntaria, la cual es solamente una ilusión que deriva de la relación entre su amígdala, el hipocampo y el nudo ventral y dorsal. La memoria emocional de la experiencia, de manera inconsciente, permite la aparición de deseos e intenciones, de modo que las decisiones surgen en el mundo límbico uno o dos segundos antes de que los hagamos conscientes. Esto se realiza de manera organizada, de tal forma que el individuo lo percibe como un autoengaño, sólo que para éste sucede de modo aparentemente sin interferencias ajenas, libre.

Sin embargo, existen impedimentos que obligan al ser humano a proceder de otra forma, todo dependiendo igual de factores como la capacidad para poder elegir el actuar de manera diferente. La cualidad de actuar de una forma $\mathrm{u}$ otra depende de la capacidad de culpabilidad del actor, en 
muchas ocasiones por cuestiones de tipo moral y no jurídico, lo que inhibe su actuar frente a los demás individuos de la sociedad. La libertad de la voluntad se centra en tres aspectos: 1) el carácter filosófico que fundamenta la libre voluntad; b) el concepto jurídico penal tradicional de la libertad de la voluntad con respecto a los conocimientos empíricos de carácter experimental entre la propia voluntad y la acción, estableciéndose de esta forma la vinculación entre el cerebro y la conducta; y 3) la posibilidad concreta de probar el poder de actuar de otro modo.

En este aspecto, existe una relación entre la neuropsicología, la rehabilitación y el derecho, siempre y cuando se tenga como objetivo el brindar apoyo a todas aquellas personas que han sufrido un daño neurológico cuando lidian con tribunales o procedimientos jurídicos; o bien, que su psique está afectada por factores que inciden en su conducta.

Existe un nivel de conocimiento de lo bueno y lo malo en nuestra sociedad; esto derivado de las sanciones que se han externado por parte de las autoridades cuando las aplican a alguien que vulnera el orden social establecido y para escarmiento de todos los demás, trayendo esto como resultado importantes connotaciones filosóficas, jurídicas y morales, en forma particular, cuando se trata de comprender los procesos cognitivos superiores vinculados con un juicio ético-jurídico, que funciona a nivel cerebral, generando la convicción de que es necesario comprender el actuar de un individuo, basado en juicios morales que derivan de los conocimientos previamente adquiridos (Fernández, 2006).

Existe un vínculo entre el pensamiento y la conducta humana. Esto no está sujeto a discusión; sin embargo, la norma jurídica puede tener dos efectos en el ser humano. Por un lado, puede disuadirlo de actuar de una manera o bien, lo condiciona a realizar alguna acción que está prohibida por la ley. En este contexto, la interpretación y la aplicación de normas jurídicas resaltan el mecanismo apto, medio posible en cuanto a su realización, y con capacidad necesaria y suficiente para poner en evidencia la natural combinación cerebro-norma.

Existe un control social que es la reacción social que las instituciones del Estado y los particulares aplican a 
todas aquellas personas que pretenden vulnerar las normas, no sólo jurídicas sino también morales y sociales, que se manifiesta de muy diversas maneras, mediante mecanismos represivos de hecho o de derecho.

En el caso de las normas sociales, se observa a través de la aprobación o desaprobación de la propia comunidad cuando se realiza una acción que no es adecuada a las reglas de etiqueta, como lo es, por citar un ejemplo, el llegar a un evento o "fiesta" vestido de manera inadecuada. La respuesta de la comunidad será la discriminación o el rechazo, lo que causará el alejamiento de la persona o su retiro del lugar. Esto derivado del propio condicionamiento social. O bien, en el caso de las reglas de etiqueta, que están vinculadas a la forma de comer, de vestirse, de actuar, como lo es el comer con las manos en un lugar donde, si bien es cierto no está prohibido, si está considerado como impropio.

\section{5.- Los derechos humanos}

Los derechos humanos existen desde el inicio de la humanidad, sin embargo, se han considerado como aquellos derechos naturales que tiene el individuo por serlo. La diferencia con la modernidad es que en un principio no se concebían como el conjunto de privilegios del gobernado, jurídicamente obligatorios e imperativos en su cumplimiento para los gobernantes; por ello, no eran recurribles dentro de la comunidad y mucho menos constituían un límite al poder público (Burgoa, 1996).

Los griegos, a pesar de que no tenían una concepción clara y precisa de lo que era la dignidad del hombre como individuo o como parte de una sociedad y autoridad política, fijaron las leyes que los ciudadanos deberían de seguir, sin importar sobre lo justo o lo injusto de éstas (Solís, 2012). El gobernante determinaba las estructuras normativas que regulaban la vida de todos sus ciudadanos sin derechos subjetivos públicos; no existía la idea de igualdad, equidad y justicia como se concibe en la actualidad (Qiintana \& Sabido, 2006). Si bien es cierto, dieron paso a la democracia en el hombre libre, no todos participaban de ella pues estaba restringida a un determinado núcleo poblacional, que tenía como principal característica su origen o su situación patrimonial. Las mujeres, los extranjeros 
y los esclavos estaban excluidos de las decisiones (Internacional, 2009).

Al discutirse lo justo y lo injusto de las leyes, el referente obligado es Antígona de Sófocles (2001), que representa el conflicto entre las leyes humanas que van en contra de las normas divinas. La obra manifiesta la defensa de valores morales universales, reafirmando que las leyes son creadas por los dioses, por lo que no hay necesidad de escribirlas porque le pertenecen a cada ser humano. La diferencia entre las leyes naturales y las dadas por el hombre radica en la naturaleza inalienable de los derechos de los seres humanos, considerándose que las normas dadas por los gobernantes no siempre serán justas ni protegerán los derechos naturales.

Las primeras constituciones pretendieron fijarle un límite al poder absoluto del Estado. La Constitución de Juan Sin Tierra de 1215 obligó al monarca a llegar a un acuerdo en donde se comprometía a no violentar los privilegios de los señores feudales y de los súbditos, como lo era el respetar las propiedades de los hombres libres, a no privarles de la vida o de la libertad, salvo que existiera una sentencia judicial. En su cláusula 39 se estableció que ningún hombre libre sería arrestado, o detenido en prisión o desposeído de sus bienes, proscrito o destellado, o molestado de alguna manera; y no dispondría sobre él, ni le pondría en prisión, sino por el juicio legal de sus pares, o por las ley del país, lo que garantizaba el derecho de audiencia (Soberanes, 2009).

Los Derechos Humanos evolucionaron después de la Segunda Guerra Mundial. A partir de su culminación se instauró un régimen internacional de protección hacia ellos, aunado a que los avances tecnológicos y los medios de comunicación permiten su difusión de manera vertiginosa. La falta de respeto a la dignidad de la persona que se instauró durante el nazismo, dio como consecuencia el desarrollo de instituciones internacionales que buscan la protección y auxilio de todos los individuos frente al poder del Estado. De esta manera se asegura el reconocimiento al ser humano de forma personal no sólo por parte de las instituciones estatales, sino también ante la comunidad jurídica internacional (Nikken, 1987).

La Declaración Universal de los Derechos Humanos del 10 de diciembre 
de 1948, es uno de los pilares más importantes de protección de los derechos humanos; aunque en la IX Conferencia Internacional Americana se aprobó la Declaración Americana de los Derechos y Deberes del Hombre, documento base de la Convención Americana sobre Derechos Humanos, que plantea la creación de organismos protectores y defensores de los derechos humanos (Del Toro, 2012).

\section{6.- Consecuencias del delito.}

Todo delito trae aparejada una sanción consistente, además de la privación de la libertad, en la reparación del daño. Si bien es cierto, el juzgador será el encargado de sancionar toda conducta que vulnere el orden jurídico establecido, tampoco indagará sobre las cuestiones que han llevado a la persona a delinquir. En México, los jueces están obligados a observar factores como el social, el económico, el educativo, pero sólo para vincular la sentencia con la pena impuesta; es decir, es determinante para el tiempo que una persona deberá pasar en prisión y para determinar el grado de peligrosidad.

Los factores sociales no son analizados por los juzgadores, sino como
163

referencias para determinar la peligrosidad de una persona. Asimismo, las sentencias no consideran las consecuencias que puede tener para la víctima la comisión de un delito.

En ese sentido no se está observando lo que señala la Constitución Política de los Estados Unidos Mexicanos (Diputados, 2019) en su artículo primero, que establece que las normas relativas a derechos humanos se deben de interpretar de acuerdo con la norma constitucional y los tratados internacionales, favoreciendo en todo tiempo a las personas la protección más amplia; es decir, se establece el principio pro persona como garantía de seguridad jurídica; principalmente porque las autoridades tienen la obligación de promover, respetar, proteger y garantizar los derechos humanos, observando primordialmente los principios de universalidad, interdependencia, indivisibilidad y progresividad.

El problema radica en que los derechos humanos pueden entenderse de diversas maneras: por un lado, la gente hace juicios de valor, mientras que los derechos humanos no hacen distinción de nacionalidad, lugar de residencia, sexo, origen nacional o étnico, color, 
religión, lengua o cualquier otra condición.

Los derechos humanos delimitan el poder del Estado, pero al mismo tiempo le exigen que adopte todas las medidas que se requieran para garantizar las condiciones de disfrute de estos. Desafortunadamente la autoridad no acepta de buena manera que le corrijan sobre sus errores y deficiencias, sino que propaga la información errónea de que los Derechos Humanos defienden a los delincuentes. Al mismo tiempo, éstos últimos sienten que no se respetan sus derechos y aprovechan, precisamente, las deficiencias de las autoridades en el debido proceso o la legalidad de los actos, para obtener una sentencia absolutoria, vulnerando, tanto el delincuente como la autoridad los derechos de las víctimas y los familiares de éstos.

\section{7.- El daño al proyecto de vida}

El delito no sólo afecta a la sociedad en su conjunto sino que afecta el futuro o planes de la persona, su vocación, sus aspiraciones, sus proyectos; afectando el rumbo o destino del individuo (Flores, 2012). Cada persona proyecta sus planes, idealiza y
164

fija metas; si bien existen causas ajenas a su voluntad que pueden evitar que se desarrollen, éstas se asocian a casos fortuitos debido a fenómenos naturales. Sin embargo, cuando ese impedimento sobreviene por una acción dañina atribuible a otro ser humano, se experimenta un vacío existencial y por ello existe la obligación de resarcir el daño.

En ese mismo sentid, el daño a una persona es aquel que frustra, destruye o hace imposible de manera total o parcial un proyecto de vida. Los delitos son de tal magnitud que truncan la realización de la persona además de comprometer su libertad y exteriorización (Cervantes, 2010). La persona deja de ser quien se había proyectado para cambiar sus valores y la misma intensidad que tenía en un principio, lo que puede conducir a la evasión a través de las drogas o el suicidio (Fernández-Sessarego, 2001).

En el Caso relativo a Claudia Ivette González, Esmeralda Herrera Monreal y Laura Berenice Ramos Monárrez, más conocido como caso “Campo Algodonero" (CorteIDH, 2009) en alusión al predio donde fueron hallados los restos humanos de las 
víctimas, en Ciudad Juárez, Chihuahua, México, la Corte Interamericana señaló que existió una actitud prejuiciosa de las autoridades respecto de la conducta de las víctimas, y fue evidente la poca intención de realizar las indagaciones pertinentes, en un primer momento para localizar a las víctimas y posteriormente para el esclarecimiento de los hechos, situación que prevaleció en el tiempo.

México indicó que la situación de la violencia que existía contra las mujeres en Ciudad Juárez derivaba de los patrones culturales existentes que se traducen en el machismo y el patriarcado. Las mujeres se habían inmerso en la vida laboral que se ofreció a través de la creación de las fabricas maquiladoras, lo que modificó los roles tradicionales, convirtiendo a las mujeres en proveedoras del hogar, lo que ocasionó un sisma al interior de las familias, naciendo la mujer competitiva e independiente y que resultó en violencia intrafamiliar o doméstica.

El psicoanálisis indica que la maldad es una capacidad destructiva dirigida hacia las personas o la sociedad como un todo, o bien a grupos específicos. Se ha insistido en que la maldad es algo natural en el ser humanos; sin embargo, es necesario domesticar la capacidad destructiva para lograr la vida común como sociedad, además de que todo daño causado debe ser reparado. Por ello, a través de la reparación se busca la restitución de la cosa obtenida mediante el delito, el pago de la misma o la indemnización. La reparación del daño no es considerada una sanción, aunque se pretende que a través de la misma se les haga justicia a las víctimas del delito.

\section{Conclusión}

Durante mucho tiempo y a través del análisis que se hiciera de la persona que delinque, se trató de explicar la razón por la cual una persona comete acciones que dañan a la sociedad en su conjunto o de manera individual sin que se prestara atención a las víctimas y el posible daño que causara en su proyecto de vida y en el de sus familiares más cercanos. El daño causado a una persona provoca una especie de efecto mariposa que afecta a la sociedad en su conjunto y que puede arrojar consecuencias enormes.

En este sentido, el Caso Campo Algodonero vs México ocasionó este tipo de efecto pues permitió la 
visibilización de un fenómeno perceptible pero no analizado en las repercusiones que este tiene dentro de la sociedad.

El delito causa un grave daño a la dignidad humana; sin embargo, no se puede perder de vita que algunas conductas antijurídicas tienen su origen en la educación y formación de los menores. El delito es un fenómeno natural, no biológico sino social porque es humano El ser un hecho natural permite conocer las causas, mecanismos $\mathrm{y}$ procesos reguladores que giran en torno al mismo. La conducta antisocial y delictiva depende del comportamiento utilitario y adaptativo para el individuo, -independientemente de que no pueda serlo para la víctima y su entorno social en su conjunto-, de acuerdo con sus características individuales, influencias recibidas y oportunidades ambientales existentes (Andrés-Pueyo, 2015).

En la actualidad es necesaria una revisión para corregir los paradigmas en torno al delito. Por un lado, es necesario prestarle mayor atención a la víctima y las consecuencias que tienen las acciones antijurídicas en los familiares y la sociedad misma y no enfocar todos los esfuerzos del Estado en encontrar la razón por la cual las personas delinquen.

De igual forma, es importante darle mayor valor a la prevención del delito y no a la reacción que se debe de tener una vez cometido este. La familia, como célula de la sociedad, tiene una labor importante a desarrollar pues en ella radica el origen de todo. La educación que se reciba en casa debe ser orientada y basada en el respeto a los derechos humanos; en caso contrario, se seguirá fallando como sociedad.

\section{Bibliografía}

Amuchategui, G. (2005). Derecho Penal. México: Oxford.

Andrés-Pueyo, A. (2015). El origen de los delitos. S. Redondo. Valencia: Tirant lo Blanch,. Revista Española de Investigación Criminológica, 1-8.

Annicchiarico, I., Gutiérrez, G., \& Pérez-Acosta, A. (2013). Neurociencias del comportamiento en revistas latinoamericanas de psicología. Avances en psicología Latinoamericana. Vol. 31, 3-32. 
Beccaria, C. (2015). Trataddo de los delitos y de las penas. Madrid: Universidad Carlos III de Madrid.

Blanco, C. (2014). Historia de la Neurociencia. El Conocimiento del cerebro y la mente desde una perspectiva interdisciplinar. Madrid: Biblioteca Nueva. .

Burgoa, I. (1996). Las Garantías Individuales. México: Porrúa.

Carrasco, E. (2007). El Pensamiento Penal de Michel Foucault. Polis, Revista de la Universidad Bolivariana, núm. 18,.

Cervantes, V. (2010). Análisis jurídico descriptivo de la violencia familiar y el daño a la persona en el derecho civil peruano. IIPSI Revista Volúmen 13, No. 1, 129-138.

CorteIDH. (2009). Caso González Y Otras ("Campo Algodonero") VS. México. Excepción Preliminar, Fondo, Reparaciones y Costas. San José C.R.: Corte Interamericana de Derechos Humanos.
Crespo, E. (2014). Libertad de voluntad, investigación sobre el cerebro y responsabilidad penal. Aproximaciones a los fundamentos del moderno debate sobre las neurociencias y derecho penal. Revista Penal México No. 6, 113-138.

De la Barrera, M. (2009). Neurociencias y su importancia en contextos de aprendizaje. Revista Digital Universitaria, vol. 10, número 4, 3-18.

Del Toro, M. (2012). La declaración universal de Derechos Humanos: un texto multidimensional. México: Comisión Nacional de los Derechos Humanos.

Diputados. (2019). Constitución Política de los Estados Unidos Mexicanos. México: Cámara de Diputados del H. Congreso de la Unión.

Fernández, A. (2006). Derecho y Neurociencia. Nómadas. Revista Crítica de Ciencias Sociales y Jurídicas, 1-9.

Fernández-Sessarego, C. (2001). Apuntes sobre el daño a la persona. En G. Borda, La Persona Humana (págs. 317-356). Argentina: La Ley. 
Flores, G. (2012). La Reparación de los daños causados a la vida e integridad corporal. Revista de Derecho Privado núm. 2, año 1, 23-73.

Foucault, M. (2003). Vigilar y castigar. Nacimiento de la Prisión. Argentina: Siblo XXI Editores.

Gamboa, A. (s.f.). El origen de la prisión y su situación actual. Letras Jurídicas, 19.

González-Salas, R. (2001). La teoría del bien juridico en el derecho penal. México: Oxford.

Hermitaño. (10 de marzo de 2007). La maldad humana y su origen. Obtenido de Apuntes de filosofía: http://apuntesdefilosofa.blogspot.com/2 007/03/la-maldad-humana-y-suorigen.html

Huertas-Díaz, O. (2011). Aproximaciones a la antropología criminal desde la perspectiva de Lombroso. Criminología, vol. 53, núm. 1, 293-306.
168

Ichard, C. (S.f.). Neurociencias. Obtenido de Universidad Pontificia Bolivariana:

http://www.upbbga.edu.co/filesupb/NE UROCIENCIAS.pdf

Internacional, A. (2009). Historia de los Derechos Humanos. Catalunya: Amnistía Internacional.

Lander, R. (20 de Noviembre de 2017). ¿Qué es la maldad y cuál es su origen? Obtenido de Dr. Romulo Lander. Médico-Psicoanalista:

http://www.romulolander.org/que-es-lamaldad-y-cual-es-su-origen/

Mata, N. (2003). Identificación de algunos factores famiiares relacionados con la delincuencia juvenil. México: Universidad Autónoma de Nuevo León.

Mencia-Ripley, A. (2016). Auto Percepción de factores causales de la delincuencia en adolescentes recluidos en la República Dominicana. Santo Domingo: Decanato de Investigación Académica, Universidad Iberoamericana. 
Montenegro, R. (29 de octubre de 2015). ¿Por qué el sujeto delinque? Diario Extra.

Narvaez, M. (2014). Neuroderecho: el sentido de la acción no está en el cerebro. Revista de Teoría del Derecho de la Universidad de Palermo, 125-148.

Nikken, P. (1987). La protección internacional de los Derechos Humanos. $\mathrm{Su}$ desarrollo progresivo. Madrid: Instituto Interamericano de Derechos Humanos.

Pavón, F. (1991). Manual de Derecho Penal Mexicano. Parte General. México: Porrúa.

Qiintana, C., \& Sabido, N. (2006). Derechos Humanos. México: Porrúa.

Redolar, D. (2002). Neurociencia: la génesis de un concepto desde un punto de vista multidisciplinario. Revista Psiquiatría, Facultad de Medicina, 346352.

Rodríguez, L. G. (2011). Reflexiones sobre César Beccaria y el Derecho Penal. En F. (. Campos, Entre libertad y castigo: Dilemas del estado contemporáneo (págs. 725-742). Méxcio: UNAM-Centro de investigaciones de Tecnología Jurídica y criminología de la Universidad Autónoma de Nuevo León.

Sammara de Araújo, J. (2017). La evolución de los fundamentos de las penas y el surgimiento de políticas actuariales basadas en la sociedad del riesgo. Revista de Derecho, Escuela de Postgrado, 62-90.

Sandoval, L., \& Martínez, D. (2008). Una revisión al estudio de la delincuencia y criminalidad. Revista de la Facultad de Ciencias Económicas: Investigación y reflexión, vol. XVI (1), 105-117.

Soberanes, J. (2009). Magna Carta (15 de junio de 1215). En J. Soberanes, Sobre el origen de las declaraciones de Derechos Humanos (págs. 165-178). México: UNAM-CNDH.

Sófocles. (2001). Antígona. Chile: Pehuen.

Solís, B. (2012). Evolución de los Derechos Humanos. En M. Moreno, \& R. (. Álvarez, El Estado laico y los Derechos Humanos 1810-2010 (págs. 77-99). México: UNAM. 


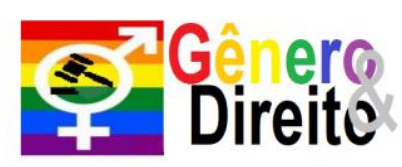

Periódico do Núcleo de Estudos e Pesquisas sobre Gênero e Direito

Centro de Ciências Jurídicas - Universidade Federal da Paraíba V. 9 - No 01 - Ano 2020 - Spanish Edition ISSN | 2179-7137 | http://periodicos.ufpb.br/ojs2/index.php/ged/index

Yenissey, I. (2009). La proporcionalidad en las penas. En D. CIENFUEGOS

SALGADO, \& M. CIFUENTES VARGAS, El Ilícito y su castigo. Reflexiones sobre la cadena perpetua, la pena de muerte y la idea de sanción en el derecho (págs. 275-286). México: Laguna.

Yurgaqui, A. (25 de mayo de 2017). ¿Por qué delinque el hombre? Obtenido de Universdad Coperativa de Colombia: https://www.ucc.edu.co/prensa/2016/Pa ginas/por-que-delinque-el-hombre.aspx 